\title{
Supervision on Social Media: Use and Perception of Facebook as a Research Education Tool in Disadvantaged Areas
}

Christoph Pimmer (corresponding author) ${ }^{1}$, Jennifer Chipps², Petra Brysiewicz², Fiona Walters², Sebastian Linxen¹, and Urs Gröhbiel ${ }^{1}$

1 University of Applied Sciences and Arts Northwestern Switzerland, 2 University of KwaZulu-Natal (UKZN), KwaZulu-Natal, South Africa

\begin{abstract}
This exploratory study investigates how a typically disadvantaged user group of older, female learners from rural, low-tech settings used and perceived a Facebook group as a research supervision and distance learning tool over time. The within-stage mixed-model research was carried out in a module of a part-time, advanced midwifery education course in rural South Africa. To address the research questions, three quantitative and qualitative surveys were repeated, pre, post, and three months post evaluation. The findings indicate that using the social media space lowered learners' threshold to accessing educational resources. The increased ease of communication was afforded in particular by using mobile phones to access the space. The analysis also suggests that the social networking site became a more integral part of students' learning environments. The learners' use of the site to discuss further course and work-related issues increased during the intervention and also remained significantly higher in the three-month, post evaluation survey, indicating the routinisation and habitualisation of this learning space. The practical implications and constraints of using social networking spaces to enhance disadvantaged groups of learners' access to educational resources are discussed.
\end{abstract}

Keywords: social media, social network site, Facebook, education, supervision, research supervision, mobile learning, m-learning, coaching, mentoring, low-income country 


\section{Introduction and Background}

This study explores how typically disadvantaged learners, in this case a female user group consisting of "digital immigrants" from rural, low-tech settings, access and accept the use of social networking and how they perceive its value in learning and research supervision. To ground our study in the literature, we briefly introduce the two underlying tenets. Firstly, with respect to access and acceptance, we outline prior studies showing how digital technologies can lead to heightened educational inclusion as well as to further discrimination of already disadvantaged groups. Secondly, we summarise extant literature on the value that social media offers to facilitate supervision and mentoring. In so doing, we also synthesise literature on heutagogy, an educational framework that emphasises self-determined learning and is thus suitable to explain both the nature of (research) supervision as well as the ways in which web 2.0 and social media provide opportunities for learning and developing capabilities.

\section{Digital Technology - Reducing or Amplifying Inequity?}

In the extant literature there are two complementary viewpoints regarding the role of digital media for disadvantaged learners. Firstly, it is recognised that the diffusion and adoption of technologies uphold, or even further amplify, educational inequality. An example being the differences between those who can access and make use of digital knowledge sources and those who do not have such means at their disposal (Warschauer \& Matuchniak, 2010). The unequal adoption and exploitation of digital technology is, inter alia, associated with socio-demographic characteristics. In this light, the learners of this study, a group of female "digital immigrants" from rural, low-tech settings in rural South Africa, may be seen as being disadvantaged in respect to at least three characteristics: age, gender, and their socio-economic background. For example, regarding age, studies observed that only a small part of older users adopt digital technologies and the internet (Carpenter \& Buday, 2007; Selwyn, Gorard, Furlong, \& Madden, 2003). Also the quality of use, for example, of social networking sites, differs from that of younger cohorts (Chu, 2010) and has being described as evoking less emotional involvement (Hayes, van Stolk-Cooke, \& Muench, 2015). Related observations were made about the association between gender and digital technology. Studies found that female users tend to have a more negative attitude towards computers and the internet (Broos, 2005; Volman, van Eck, Heemskerk, \& Kuiper, 2005). These patterns are also evident in economically disadvantaged and poor populations in developing countries. Gulati (2008) concludes in her review that although technological innovations are expected to increase equity and extend educational opportunities, many developments have actually resulted in enlarging the gap between the rich and poor, rural and urban, and between genders. Among the barriers identified are a lack of educational and technological infrastructure, the lack of skilled teachers, negative attitudes towards distance learning, social and cultural restrictions imposed on girls and women (Gulati, 2008), as well as poor socio-economic backgrounds (Sife, Lwoga, \& Sanga, 2007).

On the other hand, it is argued that the effective deployment and use of technology in educational settings can, at least to some extent, ameliorate educational and social inequalities (Warschauer \& Matuchniak, 2010) and provide learners with access to educational resources in ways not previously possible. In resource-constrained settings where more classic digital means, such as online forums, can be unpopular and unsuccessful (Van Biljon \& Dembskey, 2011), the increasing adoption of social media, and in particular of social networking sites, may offer novel affordances to educate, train, and supervise learners. At present, there are only a few studies indicating how social media is being appropriated by disadvantaged groups of learners, most of which are settled in semi-formal and 
informal educational contexts. For example, Cassaniti, Mwaikambo, and Shore (2014) observed in their descriptive study that a Facebook group, which was originally intended to help Nigerian medical laboratory scientists access e-learning courses, quickly turned into a learning space in its own right. It became a vibrant, online community of practice harbouring rich forms of knowledge creation and sharing among several thousand participants. Similar findings were reported in Asian contexts where a Facebook site was used by tens of thousands of students and practitioners to share and engage with formal learning elements. This included elements such as quiz questions, as well as reflections and discussions on professional identities, allowing for rich modes of learning and participation in professional communities (Pimmer, Linxen, \& Gröhbiel, 2012).

In rural South Africa, where this study was set, an interview-based study traced nurses who used a bundle of mobile and social media channels, including Facebook groups. They supported each other in more complex patient cases or involved their supervisors for questions and, in doing so, they facilitated different forms of social presence and professional belonging (Pimmer, Brysiewicz, Linxen, Walters, Chipps, \& Gröhbiel, 2014). Another South African study analysed the qualities of the social mobile media application WhatsApp to foster digital inclusion of poorly networked communities of South African university students (Rambe \& Bere, 2013). The mixed-method study concluded that the peer-to-peer and peer-to-lecturer discussions on WhatsApp heightened student participation and fostered the development of learning communities for knowledge creation. However, older students, in particular, conceived academic engagement after hours via WhatsApp to be disruptive to their family and private lives.

\section{Social Media, Supervision, and the Development of Self-Determined Learners}

There are only a few studies that ascertain the systematic use of social media for research supervision. This is all the more true in low and middle-income country settings. In a study similar to the present educational intervention, investigations were made into how students from previously disadvantaged South African universities with limited computer laboratories used WhatsApp to work collaboratively on a group research assignment outside of the classroom. Although the virtual conversations added to the formation of good working relations and the results pointed to an efficient sharing of workload, the educational value was limited due to the fact that not all group members had access to the platform because of phone incompatibilities and a lack of airtime (Ngaleka \& Uys, 2013). Another South African study evaluated the use of a learning management system for research supervision in a blendedlearning setting (De Beer \& Mason, 2009). While learners did not study the reading resources that were provided intensively, they appreciated the online feedback on their assessments and the availability of immediate, location, and time-independent support. This brought them closer to their supervisors, making supervision a more integral part of their research (De Beer \& Mason, 2009).

Generally speaking, (research) supervision is the process that facilitates students' development towards becoming independent and critical scholars in their respective fields (Evans, 2009). The goal of supervision resembles the facilitation of local capacity development. This is what Pachler and Redondo (2012) describe as, "equipping professionals to be able to identify problems pertinent to their context, ask the right questions, know how to seek to answer them systematically" (p. 463). In this sense, supervision can be explained by heutagogy, an emergent theory of self-determined learning (Hase \& Kenyon, 2000). Heutagogical approaches recognise the need for flexible and autonomous learning environments, where students are able to determine their paths of learning while educators provide attendant resources to support them in these processes (Hase \& Kenyon, 2000). The focus of 
heutagogy is on the development of learner capacity and capability with the goal of producing learners who are prepared to deal properly with the unforeseeable complexities of today's workplace (Blaschke, 2012). Applying heutagogy's qualities to educational approaches to complex and unpredictable settings, such as the practice-based and in-situ learning of nurses in clinical environments, has been particularly valued (Bhoyrub, Hurley, Neilson, Ramsay, \& Smith, 2010). In the field of distance learning, the renewed interest in self-directed and self-regulated learning approaches has been linked to the advent of Web 2.0 and social media because they facilitate learner centredness and selfdirectedness, for example by enabling information discovery, connectivity with others and learnergenerated content (Blaschke, 2012; Dabbagh \& Kitsantas, 2012).

\section{Materials and Methods}

\section{Research Questions, Participants, and Setting}

This research was based on an intervention that used the social networking site Facebook to facilitate research supervision for teams of learners in marginalised settings. Given the specifics of the typically marginalised user group, the first research question (RQ) was aimed at general use and acceptance of the social networking site:

RQ1: How does a group of learners from disadvantaged settings access and accept a social networking space for research supervision? How do these indicators change during and after the intervention?

The second question sought to address the educational characteristics of using a social networking space for supervision, as perceived by the learners:

RQ2: What are the educational uses and the perceived value of Facebook for supervision and learning purposes? How do these indicators change during and after the intervention?

The study was conducted in the context of a module focused on developing analytical and research skills for nurses enrolled on a part-time, advanced midwifery education programme in rural areas of KwaZulu-Natal province, South Africa. The participants $(n=47)$ were experienced clinical nurses, albeit with very limited research knowledge and experience, and also with limited digital literacy skills. A prior study of participants from the same module found that only $45 \%$ of them felt that using technological devices was more helpful than frustrating (Chipps et al., 2015).

\section{Educational Intervention and Media Space}

In this module, five teams of learners were required to develop a two-page concept paper for a joint research proposal on a midwifery topic of their choice that would be relevant to their professional work. According to the principles of heutagogy, the teams of learners developed the elements of their proposal, such as introduction, background, and methods, independently. Then, they posted these elements to the group to receive feedback from the supervisor, a skilled research academic and lecturer. In addition, they had the opportunity to ask their research supervisor questions. The supervisor also provided the general direction, for example, by communicating the overall goals of the activity and posting reading material relevant to the learners' research concepts. While some of the team members had the chance to meet occasionally on-site to develop the concept, supervision was carried out exclusively in a closed Facebook group using a mobile phone. This lasted from the end of 
January to June 2013. Social media was used to promote mutual interaction and learning across the teams. Facebook was selected because previous studies found that comparable target groups had already been using it in informal learning settings (Pimmer et al., 2014). All the teams were supported in the same space to allow for peer learning and to enable students to also learn from the supervisor's responses to the other teams.

At the beginning of the intervention, a senior technician visited the different rural sites, trained learners, and assisted them in downloading the Facebook app to their mobile phones, creating their account, and accessing the group. As indicated, only technical assistance was provided onsite; the pedagogical support was exclusively offered online. Access to the closed group was granted by the research academic.

\section{Design, Instruments, and Analysis}

The mixed methods research incorporated a within-stage, mixed-model design based on a survey with rating scales and open-ended questions (Johnson \& Onwuegbuzie, 2004). The survey instrument was developed by the researchers based on prior qualitative studies (Brysiewicz et al., 2013; Pimmer et al., 2014) and quantitative studies (Chipps et al., 2015) undertaken in similar, marginalised contexts (Pimmer, Linxen, \& Gröhbiel, 2012; Pimmer, Linxen, Gröhbiel, Jha, \& Burg, 2013). It included questions on access, use and (perceived) value, broadly following the framework established by Warschauer and Matuchniak (2010).

Closed questions using 5-point Likert scales were applied for the following: to understand the learners' perceptions of accessibility, ease of use, and use of the social networking space (RQ1); and to determine the educational value that the participants associated with its use. To gain a fuller grasp of the learners' perceptions and understanding regarding the accessibility and educational affordances of social networking space, quantitative measures were triangulated with open questions. These questions were about the positive and negative aspects which learners attributed to using the social networking space for learning and supervision. To investigate whether and, if so, how these perceptions changed during and after the end of the intervention, the survey was administered three times, before, immediately after, and three months after the end of the intervention, respectively.

Quantitative data were recoded with higher scores reflecting more positive responses and analysed using SPSSv21. To have an estimate of frequency of access, scales reporting frequency of use were recoded as such: never $=0$; nearly never $=1$; once a month $=12$; several times a month $=3 \times 12=36$; several times a week $=3 \times 52=156$; or several times a day $=365$. Changes were compared over time using the Friedman Test for repeated measures (pre, post, and three months post evaluation) and Wilcoxon Signed Rank Tests (paired) for the pre and three months post evaluations. Open-ended responses were analysed in Nvivo $8^{\mathrm{TM}}$ (Nvivo matrix function) following the principles of inductive content analysis (Mayring, 2004). That is, the individual statements were grouped and connected to themes which were then observed over time, such as throughout the pre, post, and three-month post evaluations. The core of the open question analysis was qualitative, but the distribution of themes was also analysed quantitatively, using descriptive statistics. Two researchers independently examined the comments and critically discussed their interpretations until a consensus was reached.

\section{Results}


The results are organised by integrating qualitative and quantitative findings around the two research questions. In total, 47 learners participated in this educational intervention, with 44 participants completing the surveys. A total of 37 learners completed all three sets of evaluations and the analysis is based on these participants. The participants were all female with an average age of 41.5 years (sd 7.8) with low computer use in general and 19 participants (38.2\%) reporting that they had never used Facebook before. In analysing the open-ended questions, 133 aspects were identified from the participants' comments.

\section{Access and Acceptance of the Social Media Space}

Access. Mobile phones were predominantly used to access Facebook and this pattern remained significantly higher after the intervention. In the pre-evaluation period, the average access was 49.5 times per year ( $\mathrm{sd}=106.6$, range $\mathrm{o}-365$ ). This became 196.9 times a year $(\mathrm{sd}=152.2$, range $0-365)$ in the post evaluation period, and 130.1 times a year $(s d=141.3$, range $0-365)$ three months after the intervention $\left(\mathrm{X}_{2}=25.4, \mathrm{p}=<.001\right)$.

The use of desktop and laptop technologies to access Facebook also increased significantly. Preevaluation, the average access rate was 5.8 times per year (sd26.1, range 0-156). Post evaluation, it was on average 63.8 times per year ( $\mathrm{sd}=118.7$, range $0-365)$, and three months after the evaluation it remained high at 71.0 times a year $(\mathrm{sd}=109.1$, range $0-365)(\mathrm{X} 2=36.4, \mathrm{p}=<.001)$. However, it started from a lower level and did not reach the frequency of mobile phone usage.

Acceptance. According to the analysis of the open survey questions, the use of this social media platform for learning and supervision was well-received. Although the participants were explicitly asked to indicate at least one positive and one negative aspect, approximately three-quarters (101 out of 133) of the aspects discerned in the learners' comments were positive in nature. Particularly, in the third month post evaluation, very few negative aspects were found (3 negative vs. 36 positive aspects, see Table 1). Some of the participants even developed an affective relationship to the space, expressed by statements such as "I love it" or "I just like it."

Table 1

Key Themes from Comments on the Educational Use of Facebook

\begin{tabular}{llll}
\hline Key Themes & Pre-test & Post-test & $\begin{array}{l}\mathbf{3} \text { mths post- } \\
\text { test }\end{array}$ \\
\hline Lack of media literacy & 7 & 3 & 3 \\
\hline Lack of connectivity & 3 & 5 & 0 \\
\hline Negative Aspects (total=32) & $\mathbf{1 3}$ & $\mathbf{1 6}$ & $\mathbf{3}$ \\
\hline $\begin{array}{l}\text { Ease of communication, } \\
\text { convenience, }\end{array}$ & 6 & 4 & 14 \\
\hline $\begin{array}{l}\text { Social interaction, learning from } \\
\text { peers }\end{array}$ & $\mathbf{1 4}$ & $\mathbf{1 4}$ & $\mathbf{1 0}$ \\
\hline $\begin{array}{l}\text { Knowledge acquisition and } \\
\text { learning }\end{array}$ & 4 & 9 & 3 \\
\hline Positive Aspects (total=101) & $\mathbf{3 3}$ & $\mathbf{3 2}$ & $\mathbf{3 6}$ \\
\hline
\end{tabular}


The positive perceptions were also reflected in responses to the quantitative questions about the platform's ease of use, which increased over time. The participants reported that they found it significantly easier to use Facebook on their phones over time (mean 2.2/5 ease of use rating before the intervention to $3.8 / 5$ three months post evaluation, $\mathrm{W}=3.8, \mathrm{p}<.001$ ). In addition, although the ease of use rating regarding using computers to access Facebook increased significantly (mean of 1.3/5 before the intervention to $2.8 / 5$ three months post evaluation, $W=3.1, \mathrm{p}=.002$ ), it did not reach the level of ease of the mobile phones. The increase in the ease of use over time points to the enhanced capabilities of learners in accessing and using this platform. This aspect was also directly articulated, as the following statement of a participant illustrates: "Thanks for putting us to this level now we are used to social networks which is good."

In addition, the qualitative feedback in the open survey questions reflected that the use of social media space was tied to simplified communication and to a lowered threshold for accessing information from peers, facilitators, and other resources. While only six pre-evaluation comments and four post evaluation comments highlighted ease of communication, in the three-month post evaluation, 14 participants considered this to be the most central argument in support of Facebook. In the threemonth post evaluation survey, more than one-third of the positive comments $(n=13)$ used the word "easy" with regards to the communicative properties of the space, as can be seen by the quotes below: "...it's easy to have discussions with other sisters"; “...easy to communicate and get answers immediately."

However, there was some criticism regarding the acceptance of social media (especially in the preevaluation), where Facebook was seen as an exclusive environment, not equally accessibly for all. Although the frequency of these comments decreased in the subsequent evaluations, a small number of participants felt excluded until the end of the study, with the most overt barrier being media literacy which was often explicitly tied to age: "Older people can't use it"; "Age is against me"; "It's frustrating if you are not use to it."

\section{Educational Use and Value of Facebook for Learning}

Facebook's educational role can be seen in the level of agreement with statements on its educational use and perceived value for learning in the quantitative pre, post, and three-month post evaluations. The intervention led to a significant increase in Facebook use for course-related learning through communication with work peers and other learners (22 times a year in the pre-evaluation period to 101.7 times a year in the post evaluation period $\left(X^{2}=15.6, \mathrm{p}=<.001\right)$, and 14.9 times a year in the preevaluation period to 130.8 times a year in the post evaluation period $\left(X^{2}=26.6, p=<.001\right)$ respectively $)$.

Participants also continued to use Facebook for course-related learning after the end of the official supervision period with use patterns remaining significantly high in the three-month post evaluation. Similarly, and more broadly, the nurses reported a significantly increased use of this social networking site for the discussion of clinical topics as well as to debate work-related issues with their colleagues immediately after and three months after the intervention (Table 2).

Table 2

Pre, Post, and Three-Month Post Evaluation of Perceived Facebook Use (Frequency/Year) 


\begin{tabular}{|c|c|c|c|c|c|}
\hline Item & $\begin{array}{l}\text { Pre- } \\
\text { test } \\
\text { m (sd) }\end{array}$ & $\begin{array}{l}\text { Post-test } \\
\text { m (sd) }\end{array}$ & $\begin{array}{l}3 \text { mth } \\
\text { post-test } \\
\text { m (sd) }\end{array}$ & $\begin{array}{l}\text { Test } \\
X^{2}\end{array}$ & $\begin{array}{l}\text { p- } \\
\text { value }\end{array}$ \\
\hline $\begin{array}{l}\text { I use Facebook for learning in my } \\
\text { course }(n=26)\end{array}$ & $9.6(31.4$ & $174.6(112.8$ & 101(124.1) & 38.1 & $<.001$ \\
\hline $\begin{array}{l}\text { I use Facebook to discuss issues } \\
\text { about my course with other } \\
\text { students }(n=24)\end{array}$ & $\begin{array}{l}14.9(44 . \\
1)\end{array}$ & $\begin{array}{l}130.8(120 . \\
5)\end{array}$ & $114.5(137.1)$ & 26.6 & $<.001$ \\
\hline $\begin{array}{l}\text { I use Facebook in activities that } \\
\text { relate to nursing and clinical topics } \\
(n=25)\end{array}$ & $4(10.2)$ & $108(102.4)$ & $\begin{array}{l}106.4(127.8 \\
)\end{array}$ & 29.4 & $<.001$ \\
\hline $\begin{array}{l}\text { I use Facebook to discuss about my } \\
\text { work as a nurse with } \\
\text { colleagues }(n=25)\end{array}$ & $22(51.4)$ & $\begin{array}{l}101.7(127.4 \\
)\end{array}$ & $104.2(137.1)$ & 15.6 & $<.001$ \\
\hline $\begin{array}{l}\text { I access Facebook to keep in touch } \\
\text { with my friends and family }(n=23)\end{array}$ & $\begin{array}{l}38.6(86 . \\
4)\end{array}$ & $138.3(134 \cdot 7$ & $128(146.1)$ & 14 & .001 \\
\hline
\end{tabular}

This was once again confirmed in the analysis of the open survey questions by statements such as: "Social group [on Facebook] helps us with other studies." In terms of the educational value that the participants associate with Facebook use, they describe it consistently throughout the surveys (Table 1) as a tool that facilitates learning by sharing ideas and knowledge with facilitators and peers. This is illustrated by the following comment about obtaining "information and views from other learners." Expectations about the use of Facebook in the pre-evaluation survey were often tied directly to knowledge acquisition: "I might gain some knowledge." While this perception persisted in the post and three-month post evaluations, the participants additionally described how social media use became a more integral part of their educational activities: "It's part and parcel of learning."

This can be seen in the ratings of Facebook's perceived value and importance of in education, learning, and teaching, as well as in the participants' daily lives (Table 3). Significant increases in agreement with the statements were observed over time, most strongly with respect to the importance of Facebook in learning and nursing education (from $\mathrm{m}=2.8$ in the pre-evaluation to 4.0 in the post evaluation, $\mathrm{X} 2=25.6, \mathrm{p}=<.001$, Table 3 ). However, these effects were not maintained in the threemonth post evaluation and returned to pre-evaluation levels $(\mathrm{m}=3.1, \mathrm{~W}=1.4, \mathrm{p}=.169)$. This may be due to the immediacy of the educational benefits no longer being present. The intervention did not change the students' opinions that the university should make use of social media for teaching. This opinion remained consistently high throughout the evaluations (Table 3).

Table 3

Pre, Post, and Three-Month Post Evaluation of Perceived Values of Facebook

\begin{tabular}{llllll}
\hline Item & $\begin{array}{l}\text { Pre- } \\
\text { test } \\
\mathbf{m}(\mathbf{s d})\end{array}$ & $\begin{array}{l}\text { Post- } \\
\text { test } \\
\mathbf{m}(\mathbf{s d})\end{array}$ & $\begin{array}{l}\mathbf{3} \text { mthpost } \\
\text { test m } \\
(\mathbf{s d})\end{array}$ & $\begin{array}{l}\text { Test } \\
\mathbf{X}^{2}\end{array}$ & p-value \\
& & & & \\
\hline $\begin{array}{l}\text { Social media sites such as Facebook } \\
\text { are important for my }\end{array}$ & $2.8( \pm 1.3$ & $4.0( \pm 0.9$ & $3.1( \pm 1.1)$ & 25.6 & $<.001$ \\
learning/nursing education. (n=34) & ) & ) & & & \\
\hline Social media (Facebook) is essential & $3.1( \pm 1.3$ & $3.7( \pm 1.1)$ & $2.9( \pm 1.2)$ & 15.8 & $<.001$ \\
\hline
\end{tabular}




\begin{tabular}{llllll}
\hline for teaching $(\mathbf{n}=\mathbf{3 4})$ & ) & & & & \\
\hline $\begin{array}{l}\text { Social media (Facebook) is essential } \\
\text { for learning ( }=\mathbf{3 5})\end{array}$ & $3.1( \pm 1.4$ & $3.7( \pm 1.1)$ & $3.1( \pm 1.2)$ & 13.4 & $<.001$ \\
\hline $\begin{array}{l}\text { The university should make use of } \\
\text { social media for teaching }(\mathbf{n}=\mathbf{3 2})\end{array}$ & $3.4( \pm 1.2$ & $3.4( \pm 1.3)$ & $3.1( \pm 1.2)$ & 2.2 & .325 \\
\hline
\end{tabular}

\section{Discussion and Practical Implications}

\section{Lowered Communication Threshold}

The results of this study can be discussed in the light of various conceptual perspectives. Considering the extant literature on typical discriminatory characteristics such as gender (Broos, 2005; Volman et al., 2005), age (Carpenter \& Buday, 2007; Selwyn et al., 2003), and poor socio-economic backgrounds prevailing in low resource settings (Gulati, 2008; Sife, Lwoga, \& Sanga, 2007), learners have certainly valued the accessibility of the social networking space as a supervision and learning tool. Unlike in many other studies (Gulati, 2008), the participants have shown increasingly and predominantly positive attitudes towards this particular form of distance learning. This manifested in the convenience, immediacy, and ease of use, accompanied by an increasing educational use of the social networking site during the intervention. This is in line with another investigation in South Africa which found that students' perceived ease of use of the social mobile media platform WhatsApp for academic purposes positively affected their convenience of use, i.e., the level of expediency in terms of time, place, and task execution, and finally their actual use (Bere \& Rambe, 2013). Enhanced and simplified access are apparently of value in the settings observed, where there is a naturally limited copresence of teachers and learners, with teachers and learners often living and working hundreds of kilometres apart. Considering that the cost factor was not conceived to be a dominant concern, the educational use of the social networking site embodies what Gilbert (2002) coined a "low threshold application," an information technology that is reliable, accessible, easy to learn, non-intimidating, and (incrementally) inexpensive.

\section{Habitual Use and Capability Development}

Unlike in other online learning settings where dropout and attrition can represent considerable challenges, especially compared with classroom-based education (Levy, 2007; Martinez, 2003), an anti-cyclical dynamic was observed. The findings indicate that the intervention gave rise to a significant increase in use of the social networking space for learning beyond the supervision setting. As well as significantly increasing their levels of technical competency, learners also indicated that they had started to use the platform for further learning purposes.

In the sense of heutagogy (Blaschke, 2012; Hase \& Kenyon, 2000), the intervention not only helped students to broaden their research skills but also helped them to develop communicative and learning capabilities which the learners indicate that they have used in further work and learning situations. In other words, the results suggest that the intervention triggered the appropriation and internalisation of that technology as part of the students' educational repertoire and equipped them to use social media as an instrument for further educational and professional purposes. The wider and more routinised use of the social networking site for learning also resonates with the observation that initially the participants tied the value of the networking space to cognitive dimensions (the acquisition of 
research knowledge related to the module's learning goals). However, the post evaluation surveys showed that they viewed the social networking site as a more integral part of their personal learning environment, which could be adapted according to their formal and informal learning needs (Dabbagh \& Kitsantas, 2012). This development mirrors the findings of Chipunza and Bere (2013) who reported that the academic use of the social mobile media platform WhatsApp resulted in habitual, and even addictive, use by students in their modules.

One reason for widening the observed appropriation patterns can be seen in the use of personal mobile technologies (originally made for the users' personal day-to-day communication) in more formalised settings of education and supervision (Cook, Pachler, \& Bachmair, 2013). As students predominantly used their mobile phones to access the social networking space in this study, the findings emphasise the increasing convergence of mobile and social media in educational practice (Pachler, Ranieri, Manca, \& Cook, 2012; Pimmer \& Tulenko, 2015). While both technologies are relevant with respect to widening learners' access to and participation in educational settings, per se, their convergence may provide even more salient qualities. For example, Cook, Pachler, and Bachmair (2013) posit that the use of social media on personally-owned mobile devices can scaffold equity of access to cultural resources such as learning resources, health information, or cultural events. In line with this argument, Geser (2004) conceives the cell phone as a technology with highly generalised, integrative functions. While he argues that technology tends to accentuate differences (e.g., a motorcycle with regard to gender), he argues that as cell phones are adopted relatively independently of education and family background, they can bridge at least some gaps between different social classes. Similar to the findings from the present study, his observation may be even more appropriate for social media and social networking sites. This is because prior studies have indicated that gender differences impact in a different direction with girls and women having a higher likelihood of using these technologies (Hargittai, 2007; Lenhart \& Madden, 2007), especially for academic purposes (Mazman \& Usluel, 2011).

\section{Preventing New Gaps and Promoting the Critical Use of Social Media}

In essence, the intervention facilitated learners' access to educational resources that were previously out of reach and alleviated asymmetries that are often found among students from disadvantaged areas (Rambe \& Chipunza, 2013). However, the findings must be viewed critically from at least two perspectives. Firstly, while the majority of learners valued the use of the social networking space for education, it has to be acknowledged that some inequalities between those who were included and those who felt discriminated against remained until the end of the intervention. In other words, in addition to the technology and connectivity-related challenges also observed in other studies (e.g., Rambe \& Bere, 2013), a new gap unfolded within the originally disadvantaged group, especially with respect to age. These dynamics may be mitigated, especially by incentivising and enabling the most marginalised learners within disadvantaged groups. There is also a need to provide technical and onsite support to help learners, not only at the beginning of an intervention, as in this study, but also throughout the intervention, especially addressing those learners who are only engaging to a limited extent.

Secondly, if the technology in question is to be implemented more systematically and widely into curricula to support learners in marginalised settings, there are a range of issues to be addressed that go far beyond the technical competencies of learners. These involve aspects that relate to the very nature of social media. This concern draws chiefly on its orientation towards business rather than 
education and relates to issues such as conformity, privacy, and surveillance. As Friesen and Lowe (2012) rightly argue the commercial priorities of social media networking platforms might lend themselves well to foster connectivist learning (Kop \& Hill, 2008). However, there are empirical indications that the practices of liking and resultant conviviality are deeply-anchored, structural components in the design and culture of social networking applications which give rise to conformity and heterogeneity in discourse (Hampton et al., 2014). And as, Friesen and Lowe (2012) note, these structures can make only a limited contribution to facilitating critical debate, controversy, and divisiveness as necessary components of powerful educational designs. In addition, the underlying business imperative of social media applications is directed at gathering, analysing, marketising and selling large amounts of user data (Beer, 2008). This is problematic for public education and, in particular, if data from work-based settings from the field of health care are involved, as with this study. In addition, the accumulation of social media data provides abundant opportunities for surveillance and control (Semitsu, 2011). If social media, such as Facebook, is used more systematically to educate learners from disadvantaged settings, it is not only relevant to enable the learners to use the media technically but also to help them to develop critical media literacy skills. This includes competencies and knowledge about the risks of revealing sensitive data, such as confidential images, on social networking sites where boundaries between private and public are porous (Berle, 2008; MacDonald, Sohn, \& Ellis, 2010), as well as learning about the underlying rationale and business mechanisms of social media applications.

In terms of a methodological reflection, it can be argued that the mixed-method approach has considerably strengthened the research findings through the triangulation of data sources, with its investigation of the same phenomenon through qualitative and quantitative lenses (Decrop, 1999). Many of the qualitative patterns confirmed and helped to explain the quantitative findings. In addition, the trustworthiness of the findings is further corroborated by using repeated measures, such as the three surveys. However, this study was exploratory and small-scale in nature. Additionally, it paid little attention to the nature of learning and supervision that is facilitated by the structures embedded in social media spaces and the use of this space was not compared to other digital research supervision formats. To further ascertain the affordances and constraints of supervisors and learners from disadvantaged backgrounds using a social networking space, future research is encouraged. This would provide more nuanced accounts on the nature of learning and supervision interactions, for example, through discourse analysis, and would compare the use of social networking spaces with those of other digital platforms.

\section{Conclusion}

The main contribution of this study is its analysis of how learners from disadvantaged settings perceived the access and educational value of a social networking space for research supervision. The implementation of a personal networking tool in more formal educational settings was predominantly valued by the participants. According to the participants' perceptions, the implementation of what can be characterised as a low-threshold tool not only supported the achievement of the module's learning goals. In addition, and with respect to the pedagogical framework of heutagogy, it also helped them to develop capabilities that allowed them to leverage the social media platform for further work and learning-related purposes beyond the intervention.

Leveraging freely available social networking spaces that can be conveniently accessed on learners' mobile devices may be seen as a viable way to redress educational imbalances by improving learners' 
access to previously untapped educational resources. However, to prevent new gaps from occurring among disadvantaged groups, and to facilitate a responsible and reflective use of social networking sites, learners, and, in particular, the most marginalised ones, need to be especially enabled, not only regarding the use of technology, but also with respect to the risks and challenges tied to the very nature of social media.

\section{References}

Beer, D. (2008). Social network (ing) sites... revisiting the story so far: A response to danah boyd \& Nicole Ellison. Journal of Computer-Mediated Communication, 13(2), 516-529.

Bere, A., \& Rambe, P. (2013). Extending technology acceptance model in mobile learning adoption: South African university of technology students' perspectives. Paper presented at the Proceedings of the 8th International Conference on e-Learning: ICEL 2013, Cape Town, South Africa.

Berle, I. (2008). Clinical photography and patient rights: The need for orthopraxy. Journal of Medical Ethics, 34(2), 89-92.

Bhoyrub, J., Hurley, J., Neilson, G. R., Ramsay, M., \& Smith, M. (2010). Heutagogy: An alternative practice based learning approach. Nurse Education in Practice, 10(6), 322-326.

Blaschke, L. M. (2012). Heutagogy and lifelong learning: A review of heutagogical practice and selfdetermined learning. The International Review of Research in Open and Distributed Learning, 13(1), 56-71.

Broos, A. (2005). Gender and information and communication technologies (ICT) anxiety: Male selfassurance and female hesitation. CyberPsychology \& Behavior, 8(1), 21-31.

Brysiewicz, P., Pimmer, C., Gröhbiel, U., Walters, F., Linxen, S., \& Chipps, J. (2013). The neglected grass root adoption of mobile phones as learning tools in resource-limited settings. A study from advanced midwifery education in KwaZulu-Natal, South Africa. Paper presented at the South African Association of Health Educationalists Conference, Durban, South Africa.

Carpenter, B. D., \& Buday, S. (2007). Computer use among older adults in a naturally occurring retirement community. Computers in Human Behavior, 23(6), 3012-3024.

Cassaniti, J., Mwaikambo, L., \& Shore, R. (2014). Evolution of Facebook groups: Informal e-learning among medical laboratory scientists in Nigeria. Knowledge Management \& E-Learning, 6(3), 250-261.

Chipps, J., Pimmer, C., Brysiewicz, P., Walters, F., Linxen, S., Ndebele, T., \& Gröhbiel, U. (2015). Using mobile phones and social media to facilitate education and support for rural-based midwives in South Africa. Curationis, 38(2).

Chipunza, C., \& Bere, A. (2013). Towards a novel perspective on the academic use of mobile learning applications: A case of university student perspectives. In N. Delener, L. Fuxman, F. V. Lu, S. 
Rodrigues, \& L. Rivera (Eds.), Globalizing businesses for the next century: visualizing and developing contemporary approaches to harness future opportunities (pp. 1061-1070): Global Business and Technology Association.

Chu, R. J.-C. (2010). How family support and Internet self-efficacy influence the effects of e-learning among higher aged adults-Analyses of gender and age differences. Computers \& Education, $55(1), 255^{-264}$

Cook, J., Pachler, N., \& Bachmair, B. (2013). Using social network sites and mobile technology to scaffold equity of access to cultural resources. In G. Trentin, \& M. Repetto (Eds.), Using network and mobile technology to bridge formal and informal learning (pp. 31-56). Cambridge: Woodhead Publishing.

Dabbagh, N., \& Kitsantas, A. (2012). Personal learning environments, social media, and self-regulated learning: A natural formula for connecting formal and informal learning. The Internet and Higher Education, 15(1), 3-8.

De Beer, M., \& Mason, R. B. (2009). Using a blended approach to facilitate postgraduate supervision. Innovations in Education and Teaching International, 46(2), 213-226.

Decrop, A. (1999). Triangulation in qualitative tourism research. Tourism Management, 2O(1), 157161. Retrieved from http://www.sciencedirect.com/science/article/B6V9R-3WCYW13$\underline{\mathrm{K} / 1 / \mathrm{fd} 427 \mathrm{def} 783 \mathrm{bb} 3039 \mathrm{e} 41 \mathrm{a} 4 \mathrm{f} 4 \mathrm{c} 7775903}$

Evans, L. (2009). Developing research capacity in the social sciences: A professionality based model. International Journal for Researcher Development, 1(2), 134-149.

Friesen, N., \& Lowe, S. (2012). The questionable promise of social media for education: Connective learning and the commercial imperative. Journal of Computer Assisted Learning, 28(3), 183194.

Geser, H. (2004). Towards a sociological theory of the mobile phone. Sociology in Switzerland: Sociology of the Mobile Phone. Online Publications. Retrieved from http://socio.ch/mobile/t geser1.htm

Gilbert, S. W. (2002). The beauty of low threshold applications. Campus Technology. Retrieved from https://campustechnology.com/Articles/2002/02/The-Beauty-of-Low-ThresholdApplications.aspx?Page $=2$

Gulati, S. (2008). Technology-enhanced learning in developing nations: A review. The International Review of Research in Open and Distributed Learning, 9(1).

Hampton, K., Rainie, L., Lu, W., Dwyer, M., Shin, I., \& Purcell, K. (2014). Social media and the 'spiral of silence'. Pew Report. Retrieved from http://www.pewinternet.org/2014/o8/26/socialmedia-and-the-spiral-of-silence/

Hargittai, E. (2007). Whose space? Differences among users and non-users of social network sites. Journal of Computer-Mediated Communication, 13(1), 276-297. 
Hase, S., \& Kenyon, C. (2000). From andragogy to heutagogy. Ultibase Articles, 5(3), 1-10.

Hayes, M., van Stolk-Cooke, K., \& Muench, F. (2015). Understanding Facebook use and the psychological affects of use across generations. Computers in Human Behavior, 49, 507-511.

Johnson, R. B., \& Onwuegbuzie, A. J. (2004). Mixed methods research: A research paradigm whose time has come. Educational Researcher, 33(7), 14-26.

Kop, R., \& Hill, A. (2008). Connectivism: Learning theory of the future or vestige of the past? The International Review of Research in Open and Distributed Learning, 9(3).

Lenhart, A., \& Madden, M. (2007). Social networking websites and teens: An overview. Pew Internet and American Life Project Report. Retrieved from http://www.pewinternet.org/2007/01/o7/social-networking-websites-and-teens/

Levy, Y. (2007). Comparing dropouts and persistence in e-learning courses. Computers \& Education, 48(2), 185-204.

MacDonald, J., Sohn, S., \& Ellis, P. (2010). Privacy, professionalism and Facebook: A dilemma for young doctors. Medical Education, 44(8), 805-813.

Martinez, M. (2003). High attrition rates in e-learning: Challenges, predictors, and solutions. The ELearning Developers' Journal, 14, 1-8.

Mayring, P. (2004). Qualitative content anaiysis. In U. Flick, E. von Kardorff, \& I. Steinke (Eds.), $A$ companion to qualitative research (pp. 266-269). London, Thousand Oaks, New Delhi: SAGE Publications Ltd.

Mazman, S. G., \& Usluel, Y. K. (2011). Gender differences in using social networks. Turkish Online Journal of Educational Technology-TOJET, 1O(2), 133-139.

Ngaleka, A., \& Uys, W. (2013). M-learning with whatsapp: A conversation analysis. Paper presented at the 8th International Conference on e-Learning. Cape Town, South Africa.

Pachler, N., Ranieri, M., Manca, S., \& Cook, J. (2012). Editorial: Social Networking and Mobile Learning. British Journal of Educational Technology, 43(5), 707-710.

Pachler, N., \& Redondo, A. (2012). E-mentoring and educational research capacity development: A conceptual perspective. In S. Fletcher, \& C. Mullen (Eds.), SAGE handbook of mentoring and coaching in education (pp. 459-477). London: SAGE.

Pimmer, C., Brysiewicz, P., Linxen, S., Walters, F., Chipps, J., \& Gröhbiel, U. (2014). Informal mobile learning in nurse education and practice in remote areas. A case study from rural South Africa. Nurse Education Today, 34(11), 1398-1404.

Pimmer, C., Linxen, S., \& Gröhbiel, U. (2012). Facebook as a learning tool? A case study on the appropriation of social network sites along with mobile phones in developing countries. British Journal of Educational Technology, 43(5), 726-738. 
Pimmer, C., Linxen, S., Gröhbiel, U., Jha, A., \& Burg, G. (2013). Mobile learning in resourceconstrained environments. A case study of medical education. Medical Teacher, 35(5), e1157e1165.

Pimmer, C., \& Tulenko, K. (2015). The convergence of mobile and social media: Affordances and constraints of mobile networked communication for health workers in low- and middleincome countries. Mobile Media \& Communication. Doi: 10.1177/2050157915622657.

Rambe, P., \& Bere, A. (2013). Using mobile instant messaging to leverage learner participation and transform pedagogy at a South African University of Technology. British Journal of Educational Technology, 44(4), 544-561.

Rambe, P., \& Chipunza, C. (2013). Using mobile devices to leverage student access to collaborativelygenerated resources: A case of WhatsApp instant messaging at a South African University. Paper presented at the International Conference on Advanced Information and Communication Technology for Education, ICAICTE 2013, Hainan, China.

Selwyn, N., Gorard, S., Furlong, J., \& Madden, L. (2003). Older adults' use of information and communications technology in everyday life. Ageing and Society, 23(05), 561-582.

Semitsu, J. P. (2011). From Facebook to mug shot: How the dearth of social networking privacy rights revolutionized online government surveillance. Pace Law Review, 31(1), 291-381.

Sife, A., Lwoga, E., \& Sanga, C. (2007). New technologies for teaching and learning: Challenges for higher learning institutions in developing countries. International Journal of Education and Development using ICT, 3(2).

Van Biljon, J., \& Dembskey, E. (2011). Learning tools in resource constrained environments: Learning from e-learning in the time of m-learning. Paper presented at the IDIA Conference. Lima, Peru.

Volman, M., van Eck, E., Heemskerk, I., \& Kuiper, E. (2005). New technologies, new differences. Gender and ethnic differences in pupils' use of ICT in primary and secondary education. Computers \& Education, 45(1), 35-55.

Warschauer, M., \& Matuchniak, T. (2010). New technology and digital worlds: Analyzing evidence of equity in access, use, and outcomes. Review of Research in Education, 34(1), 179-225.

\section{Athabasca} University

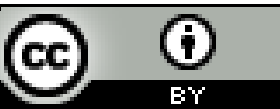

